\title{
Simple Method for Predicting American Presidential Greatness From Victory Margin in Popular Vote (1824-1996)
}

\author{
STEWART J. H. MCCANN \\ Department of Psychology \\ Cape Breton University \\ Sydney, Nova Scotia, Canada
}

\begin{abstract}
The author tested the simple method (SM) for predicting presidential greatness (S. J. H. McCann, 1999) from the winner's victory margin in the popular vote and A. M. Schlesinger Jr.'s (1986) cycles of American political history with the expert sample presidential rankings of W. J. Ridings Jr. and S. B. McIver (1997). The SM, which involves only simple calculations on minimal data available shortly after an election, predicts greatness ratings that are above average for winners with high victory margins in years of public purpose and for winners with low victory margins in years of private interest. Also, the SM predicts ratings that are below average for winners with low victory margins in public purpose years and for winners with high victory margins in private interest years. Based on the data for 42 elections from 1824 to 1996, the SM success rate was $81.0 \%$ for all elections, $85.2 \%$ for the 27 1st-term elections, $86.2 \%$ for elections after 1880 , and $94.4 \%$ for 1 st-term elections after 1880 . Chi-square analyses showed all percentages significant at the .001 level.
\end{abstract}

Key words: elections, greatness, leadership, political psychology, presidents

THE AMERICAN PRESIDENCY provides a wealth of raw data for the generation and testing of psychological theories and hypotheses that pertain to political leadership and sometimes to human behavior beyond the political realm. Also, the voluminous and constantly expanding accumulation of various presidential records, coupled with the growing number of presidencies, is beginning to permit more sophisticated quantification and statistical analysis. Consequently, much of the research on the presidency uses the historiometric approach, which Simonton (1984, p. 3) defined as "the method of testing nomothetic hypotheses

Address correspondence to Stewart J. H. McCann, Department of Psychology, Cape Breton University, PO Box 5300, Sydney, Nova Scotia, Canada B1P 6L2; stewart_mccann@ uccb.ca (e-mail). 
concerning human behavior by applying quantitative analyses to data abstracted from historical populations."

Psychologists also have continued to widen the scope of what can be studied using the historiometric strategy in this context. Consider the following diverse examples of historiometric research from the past 10 years. Bligh, Kohles, and Meindl (2004) used computerized content analysis to determine how aspects of G. W. Bush's speeches changed after the 9/11 crisis. Whitehead (1999, 2002) compared the use of the self-presentational strategies of ingratiation, self-promotion, exemplification, supplication, and intimidation in inaugural addresses of modern and traditional presidents and analyzed elements of the nonverbal communication of several presidents during their televised inaugural addresses. Emrich, Brower, Feldman, and Garland (2001) examined presidents' speeches to determine whether charisma and greatness were related to the tendency to convey images through words. Rubenzer, Faschingbauer, and Ones (2000) assessed 41 presidents using modified psychometric instruments to produce Big Five personality dimension scores. Deluga (1997, 1998, 2001) studied the relationships among presidential narcissism, proactivity, Machiavellianism, and the charismatic leadership and performance of the presidents from Washington to Reagan. McCann (1997a, 2001b) used presidential data to test hypotheses based on the theory that charismatic leaders emerge in times of crisis and, as well, found relationships among height, societal threat, and the victory margin in presidential elections from 1824 to 1992. Fiol, Harris, and House (1999) explored speeches of a sample of U.S. presidents to determine the communication strategies that were used to encourage social change. Young and French $(1996,1998)$ analyzed the relationship between the greatness and the socioeconomic status of 36 presidents and also explored the relationship between height and perceived dominance. Kowert (1996) used a Q-Sort analysis to produce personality profiles for presidents. Wong (1996) applied facialmetric analysis to features of presidents and found relationships to presidential greatness. Wang (1996) examined the effects of domestic political issues on presidential decisions to use force during international crises. Somit, Peterson, and Arwine (1994) studied links between presidential birth order, selection, and performance. And Satterfield and Seligman (1994) used content analysis to study the relationship between military actions and the degree of optimism and pessimism in the words of American president G. H. W. Bush and former Iraqi president Saddam Hussein.

One longstanding area of interest for historians, political scientists, psychologists, political pundits, and the general public is the comparative caliber, performance, and overall effectiveness of the presidents, generally referred to as their relative greatness. In a purely objective approach, presidential greatness may be impossible to define because "we can never know all the facts about a president's actions and what independent effects these actions had on historical outcomes" (Winter, 1987, p. 199). However, in a somewhat more subjective approach, sev- 
eral formal ratings and rankings of the relative greatness of American presidents have been produced by samples of experts such as historians and political scientists (e.g., Maranell, 1970; Murray \& Blessing, 1983; Ridings \& McIver, 1997; A. M. Schlesinger, 1948, 1962). Although various response formats were used to produce the ratings and rankings, there is an extraordinary degree of consistency in the evaluations. Correlations between the various indexes of greatness usually have been in the .90s (Simonton, 1986a, 1987, 2001). Where samples of experts place presidents on the greatness continuum also has been found to be generally independent of rater characteristics and to correlate in an expected fashion with other indicators of presidential eminence (Simonton, 1987, 2001).

Investigators have made considerable progress as well in determining the factors that are related to expert judgment in this context. Multiple regression equations based on several personological, situational, and zeitgeist variables have been constructed that can predict presidential greatness ratings (Kenney \& Rice, 1988; McCann, 1992; Simonton, 1986b). For example, Simonton (1986b, 2001) has found extensive support for a formula with the following six predictors: years in office, number of war years in office, presence or absence of top level scandal, whether the president was assassinated, whether the president was a national war hero before coming to office, and the intelligence of the president. In various replications through the years, the formula consistently has accounted for approximately $80 \%$ of the variance in presidential greatness variables. Using somewhat different strategies, McCann (1992) produced five formulas that were demonstrated to have variance-accounting capacities similar to Simonton's (1986b) formula. Of the five, a formula that was based on achievement drive, intelligence, height, attractiveness, tidiness, and the public purpose-private interest variable of A. M. Schlesinger Jr. (1986) may be most compelling. The six-predictor formula is open to plausible interpretation, was constructed through a rational ordering of potential predictors, and has high predictive capacity.

Central to the six-predictor formula developed by McCann (1992) is the private interest-public purpose variable that was based on the work of historian A. M. Schlesinger Jr. (1986, 1992), which also has been successfully employed in other research by McCann (e.g., 1994, 1995, 1997b, 1998, 2001a). A. M. Schlesinger Jr. has seen the political history of the United States as a cycle of shifts in national involvement that alter the social fabric and affect the tenor of the times (see also Morrow, 1987; A. M. Schlesinger, 1949). The cycle is defined by the ebb and flow of alternating phases of private interest and public purpose. The more conservative private interest phases feature an emphasis on materialism, hedonism, the pursuit of personal gratification, and the view that increased privatization and a freer economy are all that are necessary to solve society's problems. The more turbulent public purpose phases involve higher levels of idealism, passion, political commitment, social change, and an emphasis on broad efforts to improve society. The cycle is self-perpetuating and is driven mainly by the following five factors to which A. M. Schlesinger Jr. (1986, pp. 28-30) referred: (a) People inevitably become disap- 
pointed with the status quo and wish for a change of course, whether they are in a private interest phase or a public purpose phase; (b) inherent contradictions of the private interest phase foster discontent, and people tire of materialism and selfish motives; (c) the prolonged call to public action and the eventual disillusionment of the public purpose phase are emotionally exhausting and lead to a strong desire for rest, recovery, and tranquil stability; (d) a course of action somewhat successful in meeting one set of problems may not be successful with new problems; (e) when each new generation comes to occupy positions of power, it tends to repudiate the work of those it replaces and attempts to follow the ideals of those in power when it was in its own politically formative years, approximately 30 years before. According to A. M. Schlesinger Jr. (1986, 1992), the history of the nation since 1789 can be divided into private interest, transition, and public purpose years as depicted in Table 1.

McCann (1999) also used A. M. Schlesinger Jr.'s (1986) private interestpublic purpose cycle as a key variable in a different approach to the prediction of presidential greatness not based on a multiple regression formula. A simple method (SM) was created for estimating whether a president is likely to be rated

TABLE 1. Schlesinger's Years of Private Interest, Transition, and Public Purpose

\begin{tabular}{lcc}
\hline \hline Private interest & Transition & Public purpose \\
\hline $1789-1800$ & $1801-1802$ & $1803-1815$ \\
& $1816-1817$ & \\
$1818-1828$ & $1829-1830$ & $1831-1840$ \\
& $1841-1842$ & \\
$1843-1860$ & $1861-1862$ & $1863-1868$ \\
& $1869-1870$ & \\
$1871-1900$ & $1901-1902$ & $1903-1918$ \\
& $1919-1920$ & \\
$1921-1930$ & $1931-1932$ & $1933-1946$ \\
& $1947-1948$ & \\
$1949-1959$ & $1960-1961$ & $1962-1971$ \\
$1974-1990$ & $1972-1973$ & \\
& $1991-1992$ & $1993-200 ?$
\end{tabular}

Note. I based this table partly on data from "Alternative Formulas to Predict the Greatness of U.S. Presidents: Personological, Situational, and Zeitgeist Factors," by S. J. H. McCann, 1992, Journal of Personality and Social Psychology, 62, pp. 469-479; from The Cycles of American History, by A. M. Schlesinger, Jr., 1986, Boston: Houghton Mifflin; and from "The Turn of the Cycle," by A. M. Schlesinger, Jr., November 16, 1992, New Yorker, pp. 46, 48, $50,52-54$. 
as above or below average without taking into account personality variables, evaluations of administrative accomplishments, or other situational factors that would occur in the course of the presidency. In fact, one can make the prediction very soon after the election! The only variables that one needs to use McCann's (1999) SM are the margin of victory at the polls and whether the election occurred in a private interest phase or a public purpose phase. Popular vote election wins with high victory margins in public purpose years or low victory margins in private interest years predict above average presidential greatness. In contrast, election wins with low victory margins in public purpose years or high victory margins in private interest years predict below average presidential greatness.

In initial tests of the SM by McCann (1999), using the Maranell (1970) index of presidential greatness (as derived by Simonton, 1981) as the criterion, correct greatness predictions occurred for $82 \%$ of elections from 1824 to $1964,88 \%$ of elections from 1900 to $1964,86 \%$ of first-term popular vote victories from 1824 to 1964 , and $100 \%$ of first-term victories from 1900 to 1964 . In a supplementary analysis, the Murray and Blessing (1983) greatness criterion yielded similar success rates of $76 \%, 76 \%, 76 \%$, and $91 \%$, respectively.

Although the SM at first may appear to be blindly empirical, it is deeply grounded in theory stemming from the work of McCann (1997b) on threatening times and the relative election success of "strong" presidential candidates. A public purpose electorate is likely to give a wider victory margin to a candidate who appears to be strong and forceful enough to manifest the broadly desired social, economic, and political changes, whereas a candidate who displays less strength may win occasionally but probably with a lower victory margin. On the other hand, because a private interest electorate is not preoccupied with having a strong leader to foster and manage societal change, weaker leaders with other desirable characteristics often may win with high victory margins. Stronger leaders also may win but with lower victory margins. The apparent strength of a candidate is more salient in the minds of the voters in a public purpose phase but may be superseded by other qualities in a private interest phase. As well, it has been rather clear for some time (Kynerd, 1971) that raters most often base their evaluations of greatness on the apparent strength of the president. Therefore, because strength is linked to high victory margins in public purpose elections and to low victory margins in private interest elections, margin of victory in combination with A. M. Schlesinger Jr.'s phase acquires the capacity to be predictive of presidential greatness, even though the simple correlation between the degree of success at the polls and presidential greatness is practically zero (Simonton, 1987; Winter, 1987, p. 199).

I conducted the present study to test the SM with more recent rankings of presidential greatness produced by Ridings and McIver (1997). The new greatness index allowed the sample to be enlarged from 33 elections through 1964 in the McCann (1999) study to 43 elections through 1996. According to the SM, it was predicted that popular vote winners with high victory margins in public pur- 
pose phases and low victory margins in private interest phases would receive above average greatness rankings, while popular vote winners with low victory margins in public purpose phases and high victory margins in private interest phases would receive below average greatness rankings.

\section{Method}

\section{Measures}

Presidential greatness. The overall rankings of the presidents from 1 (highest) to 41 (lowest) produced by Ridings and McIver (1997), which were based on the judgments of 719 expert survey respondents, served as the measure of presidential greatness. Simonton (2001) provided reliability and validity data to show that the Ridings and McIver variable is quite consistent with earlier presidential evaluations.

Victory margin. In the present study, I used the same operational definition of victory margin as in McCann (1997b). Victory margin was the simple additive composite of the $z$ scores of (a) the winning candidate's percentage of the popular vote, (b) the difference between the winner's and the second-place finisher's percentage of the popular vote, and (c) the winner's percentage of the total popular vote taken by the winner and the second-place finisher. McCann (1999) found that, for the purposes of the SM, the median of the unweighted composite of the three raw scores, which was 114.6, suitably separated high and low victory margins. It also should be noted that the SM has to do with popular vote winners. Therefore, Jackson was a "winner" in 1824, as was Cleveland in 1884, and Tilden in 1876.

A. M. Schlesinger Jr's cycles. I classified the years since 1824, the first year with a popular vote presidential election, as private interest years or public purpose years as in McCann (1999, p. 8), based on A. M. Schlesinger Jr. (1986, 1992). Private interest years included 1824-1829, 1842-1861, 1870-1901, 1920-1931, 1948-1960, and 1973-1991. Public purpose years included 1830-1841, 1862-1869, 1902-1919, 1932-1947, 1961-1972, and 1992-present. In this classification scheme, the first transition year is included in the preceding phase, and the second transition year is included in the following phase, to produce a dichotomous variable.

\section{Procedure}

I categorized the elections from 1824 to 1996 according to private interest versus public purpose and high versus low victory margin, using the total victory margin composite raw score of 114.6 from McCann (1999) as the separation point. The rankings of the popular vote winners in each quadrant then were compared. I 
excluded Tilden, who "won" in 1876, of course, because he was not rated in the Ridings and McIver (1997) poll.

\section{Results}

Table 2 displays the Ridings and McIver (1997) rankings for winners of elections in the four combinations of A. M. Schlesinger Jr.'s phases and high and low victory margins. It is evident that the pattern of rankings in the four quadrants is in line with the predictions that I based on the SM. That is, winners with high victory margins in public purpose phases or low victory margins in private interest phases received higher greatness rankings, whereas winners with low victory margins in public purpose phases or high victory margins in private interest phases received lower greatness rankings. With Van Buren excluded because he received the median ranking of 21, the success rate for the SM was $81.0 \%$ for all 42 elections, $85.2 \%$ for all 27 first-term elections, 86.2\% for all elections after 1880, and $94.4 \%$ for all first-term elections after 1880 . Chi-square analyses showed all percentages to be significant at the .001 level.

\section{Discussion}

The SM proved to be quite successful in predicting whether a president would receive a greatness ranking above or below the median of the overall rankings from the large sample of experts involved in the Ridings and McIver (1997) project. As in McCann (1999), the SM was especially efficient in regard to predictions that were based on first-term elections. Excluding Van Buren in 1836 because he received the median ranking, correct predictions occurred for all 27 popular vote winners except Taylor in 1848, Pierce in 1852, Garfield in 1880, and Eisenhower in 1952. When the 15 second-or-later elections were included, the only additional winners that did not result in successful predictions were Jackson in 1828, Wilson in 1916, Eisenhower in 1956, and Nixon in 1972. However, the rankings for Jackson, Wilson, and Nixon, of course, were successfully predicted by the SM with data based on first-term elections.

What might have contributed to the prediction failures? Taylor, Pierce, and Garfield each had a first, and only, win in a private interest phase with a low victory margin but received a low greatness ranking, while Eisenhower won in a private interest phase with a high victory margin but received a high ranking. As stated in McCann's 1999 study, Taylor's ranking probably suffered because of his less-than-half term in office, and Pierce was a 49th ballot "dark horse" candidate afflicted by a string of deep personal tragedies just prior to taking office. Perhaps Garfield also simply did not serve long enough to warrant a higher ranking. Whereas Taylor, Pierce, and Garfield consistently have received low rankings in projects for rating presidential greatness, Eisenhower's evaluations have been mixed (Simonton, 1987, p. 183). As a result, the SM prediction was successful 
TABLE 2. Ridings and McIver Greatness Rankings According to Victory Margin and Schlesinger's Phases

\begin{tabular}{|c|c|c|c|c|c|}
\hline \multicolumn{3}{|c|}{ Private interest } & \multicolumn{3}{|c|}{ Public purpose } \\
\hline Year & Winner & Ranking & Year & Winner & Ranking \\
\hline \multicolumn{6}{|c|}{ High margin } \\
\hline 1828 & Jackson & 8 & 1832 & Jackson & 8 \\
\hline $1856^{\mathrm{a}}$ & Buchanan & 40 & $1836^{\mathrm{a}}$ & Van Buren & 21 \\
\hline 1872 & Grant & 38 & 1864 & Lincoln & 1 \\
\hline $1920^{\mathrm{a}}$ & Harding & 41 & $1904^{\mathrm{a}}$ & T. Roosevelt & 5 \\
\hline $1924^{\mathrm{a}}$ & Coolidge & 33 & $1908^{\mathrm{a}}$ & Taft & 20 \\
\hline $1928^{a}$ & Hoover & 24 & $1912^{\mathrm{a}}$ & Wilson & 6 \\
\hline $1952^{\mathrm{a}}$ & Eisenhower & 9 & $1932^{\mathrm{a}}$ & F. Roosevelt & 2 \\
\hline 1956 & Eisenhower & 9 & 1936 & F. Roosevelt & 2 \\
\hline $1980^{\mathrm{a}}$ & Reagan & 26 & 1940 & F. Roosevelt & 2 \\
\hline 1984 & Reagan & 26 & 1944 & F. Roosevelt & 2 \\
\hline $1988^{a}$ & G. H. W. Bush & 22 & $1964^{\mathrm{a}}$ & L. Johnson & 12 \\
\hline & & & 1972 & Nixon & 32 \\
\hline \multicolumn{6}{|c|}{ Low margin } \\
\hline $1824^{\mathrm{a}}$ & Jackson & 8 & $1840^{\mathrm{a}}$ & W. Harrison & 35 \\
\hline $1844^{\mathrm{a}}$ & Polk & 11 & $1868^{\mathrm{a}}$ & Grant & 8 \\
\hline $1848^{\mathrm{a}}$ & Taylor & 29 & 1916 & Wilson & 6 \\
\hline $1852^{\mathrm{a}}$ & Pierce & 37 & $1968^{\mathrm{a}}$ & Nixon & 32 \\
\hline $1860^{\mathrm{a}}$ & Lincoln & 1 & $1992^{\mathrm{a}}$ & Clinton & 23 \\
\hline $1880^{\mathrm{a}}$ & Garfield & 30 & 1996 & Clinton & 23 \\
\hline $1884^{\mathrm{a}}$ & Cleveland & 16 & & & \\
\hline 1888 & Cleveland & 16 & & & \\
\hline 1892 & Cleveland & 16 & & & \\
\hline $1896^{\mathrm{a}}$ & McKinley & 17 & & & \\
\hline 1900 & McKinley & 17 & & & \\
\hline $1948^{a}$ & Truman & 7 & & & \\
\hline $1960^{\mathrm{a}}$ & Kennedy & 15 & & & \\
\hline $1976^{\mathrm{a}}$ & Carter & 19 & & & \\
\hline
\end{tabular}

Note. I based this table partly on data from "A Simple Method for Predicting Presidential Greatness From Popular Vote Victory Margin,” by S. J. H. McCann, 1999, The Journal of Psychology, 133, pp. 5-14; and from Rating the Presidents: A Ranking of U.S. Leaders From the Great and Honorable to the Dishonest and Incompetent, by W. J. Ridings, Jr., and S. B. McIver, 1997, Secaucus, NJ: Citadel.

aFirst elections.

with the Maranell (1970) greatness ratings but unsuccessful with the Murray and Blessing (1983) ratings in McCann's 1999 research, and also with those of the present study. Eisenhower remains the only president since Garfield whose rating was not predicted correctly by the SM on the basis of first-term elections. 
McCann (1999) developed the SM on the basis of the data of 33 elections between 1824 and 1964, excluding those of W. H. Harrison in 1840, Tilden in 1876, and Garfield in 1880. In the present study, I added the 10 elections of W. H. Harrison, Garfield, Nixon, Carter, Reagan, G. H. W. Bush, and Clinton. For these additional elections, the success rate of the SM was $80.0 \%$, compared to $82.0 \%$ for the Maranell (1970) greatness index and $76.0 \%$ for the Murray and Blessing (1983) ratings in McCann's 1999 research. For the additional seven firstterm elections, the respective success rates were $85.7 \%, 82.0 \%$, and $76.0 \%$. Therefore, the SM predicted about as well for the new elections as for the elections on which it was formulated.

The SM is an easy-to-use heuristic_-involving short and simple calculations that one performs on minimal data that are available shortly after an electionthat evidently can predict quite reliably whether a newly elected president will be seen later as above or below average in greatness. For example, consider the 1904 election. In regard to the popular vote, Theodore Roosevelt won 56.4\%, and Parker won $37.6 \%$, for a total of $94.0 \%$. The difference between Roosevelt and Parker is $18.8 \%$ (i.e., $56.4 \%-37.6 \%$ ). Roosevelt obtained $60.0 \%$ of the total secured by Roosevelt and Parker combined (i.e., 56.4/94.0 × 100\%). Therefore, the rawscore victory margin composite is 135.2 (i.e., $56.4+18.8+60.0$ ). The election was in a public purpose phase, and the victory margin composite value of 135.2 is greater than 114.6. Therefore, the SM would predict Theodore Roosevelt to be above average, and this prediction is verified by the ranking of 5 .

In contrast, the use of regression equations such as those put forth by Simonton (1986b) and McCann (1992) is much more complex. The formula used by Simonton $(1986 b)$ to predict $z$ scores of greatness is .15 (years in office) +.21 (war years $)-1.44$ (scandal $)+.73$ (assassinated $)+.87$ (war hero $)+.26$ (intelligence $)-$ 1.10. The most compelling formula produced by McCann (1992) is .05 (variable based on A. M. Schlesinger Jr.'s cycle) + .36 (achievement drive) - .25 (tidiness) +.27 (intelligence) +.11 (height) -.21 (attractiveness) -7.77 . Although the more complex regression formulas clearly produce more informative and finely graduated greatness predictions for research purposes, they do require much more data that often are very difficult to procure. It also is impossible to use any of the regression formulas to predict greatness while a president is still in office. Furthermore, for a simple above or below average prediction, the more complex formulas may not be more successful than the SM. For instance, on the basis of the 27 first-term elections, excluding that of Van Buren, who received the median rank, predictions of the overall Ridings and McIver (1997) rankings using the SM were incorrect for only four presidents (Taylor, Pierce, Garfield, and Eisenhower). On the basis of Simonton's (1986a) greatness predictions for the presidents up to Reagan and Simonton's (2001) predictions for G. H. W. Bush and Clinton, a supplementary tabulation for the same 26 presidents showed that Simonton's six-variable formula also produced incorrect dichotomous predictions of the Ridings and McIver (1997) rankings for four presidents (Taft, Carter, Reagan, and Clinton). 
The SM does have some limitations, of course. McCann (1999) pointed out the following six:

1. The SM produces only dichotomous "above average" or "below average" predictions rather than the finely scaled continuous predictions of the multiple regression formulas.

2. The SM may provide different predictions for presidents who win more than once. However, on the basis of accrued empirical evidence, more faith generally should be placed on the prediction from the first win.

3. Categorizing an election year as one of public purpose or private interest may be somewhat problematic in the future because the phase transition may be clearer in retrospect than when it is actually happening. Until now, the determination of the phase changes has been made by A. M. Schlesinger Jr. (1986, 1992). Based on his historical theory of cyclical fluctuations in public purpose and private interest phases, others may be able to make an astute judgment call. Alternatively, a more empirical approach eventually might be developed to more objectively determine phase shifts.

4. The SM cannot provide predictions for those who came to office before the institution of the popular vote in 1824 .

5. The SM cannot provide predictions for those who are not elected president.

6. The SM cannot provide predictions for presidents who came to office even though they lost the popular vote contest.

What does the SM predict for G. W. Bush? Strictly speaking, according to the preceding sixth limitation of the SM, it cannot make a prediction. However, one may offer cautious speculation through extrapolation. Bush had a composite "margin of victory" score under the separation value of 114.6 in a public purpose phase. Others to receive a low victory margin in a public purpose phase and consequently predicted by the SM to be below average in greatness were W. Harrison in 1840, Grant in 1868, Wilson in 1916, Nixon in 1968, and Clinton in 1992 and 1996. Of these, only Wilson defied expectation and received an above average position in the Ridings and McIver (1997) rankings. Wilson, however, was predicted to be above average on the basis of the 1912 election. So, on the basis of the 2000 election, G. W. Bush is predicted to be below average. The same prediction would have been made for Gore had he secured the office with a similarly close margin of victory.

It does appear that if recurring historical patterns are at all indicative of the future, the SM may have lasting predictive utility, despite the noted limitations. According to the data presented here, those presidents who are most likely to receive the praises of posterity for their political leadership have popular vote election victories, especially first-term election victories, with wide victory margins in public purpose phases or narrow victory margins in private interest phases. In the present project, this has been demonstrated to be the case over a span of 173 years of American history. 


\section{REFERENCES}

Bligh, M. C., Kohles, J. C., \& Meindl, J. R. (2004). Charting the language of leadership: A methodological investigation of President Bush and the crisis of 9/11. Journal of Applied Psychology, 89, 562-574.

Deluga, R. J. (1997). Relationship among American presidential charismatic leadership, narcissism, and rated performance. Leadership Quarterly, 8, 49-65.

Deluga, R. J. (1998). American presidential proactivity, charismatic leadership, and rated performance. Leadership Quarterly, 9, 265-291.

Deluga, R. J. (2001). American presidential Machiavellianism: Implications for charismatic leadership and rated performance. Leadership Quarterly, 12, 339-363.

Emrich, C. G., Brower, H. H., Feldman, J. M., \& Garland, H. (2001). Images in words: Presidential rhetoric, charisma, and greatness. Administrative Science Quarterly, 46, 527-557.

Fiol, C. M., Harris, D., \& House, R. (1999). Charismatic leadership: Strategies for affecting social change. Leadership Quarterly, 10, 449-482.

Kenney, P. J., \& Rice, T. W. (1988). The contextual determinants of presidential greatness. Presidential Studies Quarterly, 18, 161-169.

Kowert, P. A. (1996). Where does the buck stop? Assessing the impact of presidential personality. Political Psychology, 17, 421-452.

Kynerd, T. (1971). An analysis of presidential greatness and "presidential rating." Southern Quarterly, 9, 309-329.

Maranell, G. M. (1970). The evaluation of presidents: An extension of the Schlesinger polls. Journal of American History, 57, 104-113.

McCann, S. J. H. (1992). Alternative formulas to predict the greatness of U.S. presidents: Personological, situational, and zeitgeist factors. Journal of Personality and Social Psychology, 62, 469-479.

McCann, S. J. H. (1994). Crises and Schlesinger's cycles of American history (1789-1992). Psychological Reports, 74, 642.

McCann, S. J. H. (1995). Presidential candidate age and Schlesinger's cycles of American history (1789-1992): When younger is better. Political Psychology, 16, 749-755.

McCann, S. J. H. (1997a). Threatening times and the election of charismatic U.S. presidents: With and without FDR. The Journal of Psychology, 131, 393-400.

McCann, S. J. H. (1997b). Threatening times, "strong" presidential popular vote winners, and the margin of victory (1824-1964). Journal of Personality and Social Psychology, $73,160-170$.

McCann, S. J. H. (1998). The extended American social, economic, and political threat index (1788-1992). The Journal of Psychology, 132, 435-449.

McCann, S. J. H. (1999). A simple method for predicting presidential greatness from popular vote victory margin. The Journal of Psychology, 133, 5-14.

McCann, S. J. H. (2001a). Birth order of past presidents and Schlesinger's history cycles: Support for Stewart's leadership theory. Psychological Reports, 88, 375-376.

McCann, S. J. H. (2001b). Height, societal threat, and the victory margin in presidential elections (1824-1992). Psychological Reports, 88, 741-742.

Morrow, L. (1987, March 30). A change in the weather. Time, 1987, 28-34, 37.

Murray, R. K., \& Blessing, T. H. (1983). The presidential performance study: A progress report. Journal of American History, 70, 535-555.

Ridings, W. J., Jr., \& McIver, S. B. (1997). Rating the presidents: A ranking of U.S. leaders from the great and honorable to the dishonest and incompetent. Secaucus, NJ: Citadel.

Rubenzer, S. J., Faschingbauer, T. R., and Ones, D. S. (2000). Assessing the U.S. presidents using the revised NEO Personality Inventory. Assessment, 7, 403-420. 
Satterfield, J. M., \& Seligman, M. E. P. (1994). Military aggression and risk predicted by explanatory style. Psychological Science, 5, 77-82.

Schlesinger, A. M. (1948, November 1). Historians rate the U.S. presidents. Life, 25, 65-66, 68, 73-74.

Schlesinger, A. M. (1949). Paths to the present. New York: MacMillan.

Schlesinger, A. M. (1962, July 29). Our presidents: A rating by 75 historians. New York Times Magazine, 1962, 12-13, 40-41, 43.

Schlesinger, A. M., Jr. (1986). The cycles of American history. Boston: Houghton Mifflin.

Schlesinger, A. M., Jr. (1992, November 16). The turn of the cycle. New Yorker, 1992, 46, $48,50,52-54$.

Simonton, D. K. (1981). Presidential greatness and performance: Can we predict leadership in the White House? Journal of Personality, 49, 306-323.

Simonton, D. K. (1984). Genius, creativity, and leadership: Historiometric inquiries. Cambridge, MA: Harvard University Press.

Simonton, D. K. (1986a). Presidential greatness: The historical consensus and its psychological significance. Political Psychology, 7, 259-283.

Simonton, D. K. (1986b). Presidential personality: Biographical use of the Gough Adjective Check List. Journal of Personality and Social Psychology, 51, 149-160.

Simonton, D. K. (1987). Why presidents succeed: A political psychology of leadership. New Haven, CT: Yale University Press.

Simonton, D. K. (2001). Predicting presidential performance in the United States: Equation replication on recent survey results. The Journal of Social Psychology, 141, 293-308.

Somit, A., Peterson, S. A., \& Arwine, A. (1994). Birth order as a factor in presidential selection and performance. Social Science Journal, 31, 407-419.

Wang, K. H. (1996). Presidential responses to foreign policy crises: Rational choice and domestic politics. Journal of Conflict Resolution, 40, 68-97.

Whitehead, G. I., III. (1999). Self-presentational strategies of modern and traditional presidents. Journal of Social Behavior and Personality, 14, 479-490.

Whitehead, G. I., III. (2002). The use of hand gestures and smiles in the inaugural addresses of presidents of the United States. The Journal of Social Psychology, 142, 670-672.

Winter, D. G. (1987). Leader appeal, leader performance, and the motive profiles of leaders and followers: A study of American presidents and elections. Journal of Personality and Social Psychology, 52, 196-202.

Wong, D. T. (1996). All the presidents' faces: Facialmetric analyses of personality profiles and greatness ratings in United States leaders. Dissertation Abstracts International, 56 (9-B), 5214.

Young, T. J., \& French, L. A. (1996). Social class and perceived competence of U.S. presidents. Perceptual and Motor Skills, 83, 330.

Young, T. J., \& French, L. A. (1998). Heights of U.S. presidents: A trend analysis for 1948-1996. Perceptual and Motor Skills, 87, 321-322.

Received January 26, 2004

Accepted September 28, 2004 
Copyright of Journal of Social Psychology is the property of Heldref Publications and its content may not be copied or emailed to multiple sites or posted to a listserv without the copyright holder's express written permission. However, users may print, download, or email articles for individual use. 